\title{
168. Outline of the Author's Suggested Pluralism for Senility
}

\author{
By Tomosaburo OGATA, M.J.A. \\ Research Institute for Gerontology
}

(Comm. Dec. 12, 1962)

The author expresses his wholehearted approval for a highly commendable opinion of many German medical scientists that an entity of senility should be searched for in life phenomena in an entire span of human life.

Based on our studies during past more than 30 years on endocrine function of the salivary glands, we were also able to grasp the entity by comparative study of various diseases in different stages of human life elucidating asialoadenism, endocrinological hypoand a-function of the salivary glands as a cause of different patterns of manifestation of same disease in each of growing, puberty, and involution stages of human life.

According to results of our study, asialoadenism in growing stage results dwarf showing short extremities (achondroplastic dwarf) due to hypoplasia of the salivary glands in fetal period. Kushin-Beck's disease is caused by atrophy and degeneration of striated ducts of the salivary glands affected by toxic agent in drinking water (furvic acid-disintegration product of plant leaves buried in the earth) in infant period.

On the other hand, asialoadenism after the growing stage which is due to involution of the parotid glands (conversion of the parenchyma into fat tissue) produces 'apparent' senility.

Parotin, hormone of the salivary glands is a physiologically essential protein for nutrition and growth of various tissues mainly belonging to the mesenchymal system.

When, therefore, this substance is deficient in these various stages of human life, a characteristic degenerative changes for respective stages will be resulted in tissues of the mesenchymal system including epidermis.

In full study, however, comparing these changes, it is recognizable that they are changes of the same entity. Loss of elasticity of tissue by degeneration and disappearance of elastic fibers and skeletal deformation which is primarily due to degeneration and destruction of the cartilage or chondroid tissue (epiphysial cartilage, arthrodial cartilage, intervertebral cartilage) are the most conspicuous instances among these common changes.

In experimental sialoadenectomized animals, histological pictures 
of hyperfunction of the pituitary, thyroid and Langerhans' islands of pancreas together with cortical atrophy of adrenals are always seen.

In asialoadenism in various stages of human life, exactly the same pictures are proved. This fact shows that deficiency of the salivary gland hormone is a main causative factor of these changes.

The onset of involution of the parotid glands which is the main endocrine among the salivary glands is insidious and gradual beginning in the early puberty. Therefore, the 'apparent' senility of various tissues of the mesenchymal system is primarily manifested as increased fatiguability of the muscle tissue and secondarily various changes which give senile appearance to an individual as his age increases.

In involution stage (after about the age of 45), when asialoadenism is accompanied by sex hormone deficiency due to involution of the sex glands (more prominent in female), the 'apparent' senility which is attributable to the salivary gland hormone deficiency is further advanced with changes of tissues and organs (sex organs, skin etc.) which have been manifesting primary and secondary sex characters controled by both salivary and sex hormons (double control) in puberty.

Thus, deficiency of the salivary gland hormone is evidently the main etiological factor of the 'apparent' senility.

Further, together with the deficiency of not only sex but other hormones and with accumulated defective life conditions for a long period of time, the 'apparent' senile changes are more advanced.

Therefore, the 'apparent' senility would be subsided theoretically by removal of all these factors but above all if salivary gland hormone deficiency which is the main factor is surmounted the condition will be restored and in practice this is actually the case.

It may be said that at least in theoretical pathology it is proved that many of geriatric diseases (adult diseases) are manifested in the mesenchymal tissue (mesenchymodystrophy) in which the 'apparent' senility has prodromally appeared.

Therefore, if problems of the 'apparent' senility can be totally solved, prevention of geriatric disease will be succeeded.

The author has called physiological changes in whole body autogenously appeared nearly at the age of 60 (true senile stage) by consumption of various living tissues as 'true' senility and been advocating to differentiate it from above mentioned 'apparent' senility.

The nerve tissue (central nervous system) and acinous epithelial tissues (liver, kidney, pancreas and other various endocrine glands) fall into senility in this 'true' senile stage and manifest the senile atrophy. 
Many of the old can not survive their natural allotted span of lives but die with various geriatric diseases.

When the old fortunately survive their entire allotted lives, as in rare cases, they die naturally by decline of function of these organs especially nerve tissue with advanced senile changes.

This is the outline of the author's suggested pluralism of senility. 